\title{
PENGARUH MODEL PEMBELAJARAN COOPERATIVE SCRIPT DAN CIRC DALAM KEMAMPUAN PEMECAHAN MASALAH DITINJAU DARI GAYA KOGNITIF
}

\author{
Arum Marfungah ${ }^{1}$, Puji Nugraheni' ${ }^{2}$, Dita Yuzianah ${ }^{3}$ \\ ${ }^{1,2,3}$ Universitas Muhammadiyah Purworejo, Jl. K.H. Ahmad Dahlan 3 Purworejo 54111 \\ arummarfungah379@gmail.com
}

\begin{abstract}
This study aims to determine the Cooperative Script learning model provides better problem-solving abilities than the CIRC learning model for students who have FI and FD cognitive styles. This type of research is quasi experimental. The research population was all grade VII students of SMP N 2 Kepil in the 2019/2020 academic year. The research sample was 2 classes, namely class VII C as the experimental class 1 with the Cooperative Script learning model and class VII D as the experimental class 2 with the CIRC learning model. The results of the study with $\alpha=5 \%$ obtained the value of $F_{a b}=15.52$ with $D K=\{F \mid F>4.08\}$ then $F_{a b} \in D K$ so that H0AB is rejected, meaning that there is an interaction between learning models and cognitive styles on problem solving abilities. Because $\mathrm{H}_{0 \mathrm{AB}}$ was rejected, it was continued with a double comparative test, the average score of students with the Cooperative Script learning model for students who had FI and FD cognitive styles was 66.42 and the average score of students with the CIRC learning model for students who had cognitive styles FI and FD are 71.84. It can be concluded that the CIRC learning model provides better problem-solving abilities than the Cooperative Script learning model for students who have FI and FD cognitive styles.
\end{abstract}

Keywords: Cooperative Script, CIRC, Problem Solving Ability, Cognitive Style.

\begin{abstract}
Abstrak
Penelitian ini bertujuan untuk mengetahui model pembelajaran Cooperative Script memberikan kemampuan pemecahan masalah yang lebih baik daripada model pembelajaran CIRC pada siswa yang memiliki gaya kognitif FI dan FD. Jenis penelitian ini adalah eksperimental semu. Populasi penelitian yaitu semua siswa kelas VII SMP N 2 Kepil Tahun Pelajaran 2019/2020. Sampel penelitian 2 kelas, yaitu kelas VII C sebagai kelas eksperimen 1 dengan model pembelajaran Cooperative Script dan kelas VII D sebagai kelas eksperimen 2 dengan model pembelajaran CIRC. Hasil penelitian dengan $\alpha=5 \%$ diperoleh nilai $\mathrm{F}_{\mathrm{ab}}=15,52$ dengan $\mathrm{DK}=$ $\{\mathrm{F} \mid \mathrm{F}>4,08\}$ maka $\mathrm{F}_{\mathrm{ab}} \in \mathrm{DK}$ sehingga $\mathrm{H}_{0 \mathrm{AB}}$ ditolak, artinya terdapat interaksi antara model pembelajaran dan gaya kognitif terhadap kemampuan pemecahan masalah. Karena $\mathrm{H}_{0 \mathrm{AB}}$ ditolak maka dilanjutkan dengan uji komparasi ganda, diperoleh nilai rata-rata siswa dengan model pembelajaran Cooperative Script pada siswa yang memiliki gaya kognitif FI dan FD adalah 66,42 dan nilai rata-rata siswa dengan model pembelajaran CIRC pada siswa yang memiliki gaya kognitif FI dan FD adalah 71,84. Dapat disimpulkan bahwa model pembelajaran CIRC memberikan kemampuan pemecahan masalah yang lebih baik daripada model pembelajaran Cooperative Script pada siswa yang memiliki gaya kognitif FI dan FD.
\end{abstract}

Kata kunci: Cooperative Script, CIRC, Kemampuan Pemecahan Masalah, Gaya Kognitif.

\section{PENDAHULUAN}

Kemampuan pemecahan masalah bagi siswa perlu diupayakan agar siswa mampu mencari solusi berbagai permasalahan, baik pada bidang matematika maupun masalah dalam kehidupan sehari-hari yang semakin kompleks (Ulya, 2015). Kemampuan pemecahan masalah dalam matematika dipengaruhi oleh beberapa faktor yaitu pengetahuan awal, apresiasi matematika, dan kecerdasan logis matematis (Suparta dkk, 2016). Faktor tersebut muncul karena setiap individu memiliki perbedaan. Dimensi-dimensi perbedaan individu antara lain adalah intelegensi, kemampuan berpikir logis, kreativitas, gaya kognitif, kepribadian, nilai, sikap, dan minat (Ulya, 2015). Salah satu perbedaan individu yang perlu dipertimbangkan, khususnya pendidikan matematika adalah gaya kognitif. Gaya kognitif merupakan variabel penting yang mempengaruhi pilihan-pilihan siswa dalam 
bidang akademik, kelanjutan perkembangan akademik, bagaimana siswa belajar serta bagaimana siswa dan guru berinteraksi didalam kelas (Slameto, 2015).

Liu \& Ginther (1991) mengatakan bahwa "Gaya kognitif mengacu pada kecenderungan yang konsisten dan karakteristik individu mempersepsi, mengingat, pengorganisasian, pengolahan, pemikiran, dan pemecahan masalah". Idris (dalam Ulya, 2015) mengidentifikasi 3 tipe gaya kognitif, yaitu Field Dependent (FD), Field Intermediate (FDI), dan Field Independent (FI). Individu FD cenderung bekerja dengan motivasi eksternal, yaitu mencari bimbingan dan petunjuk dari orang lain. Individu FDI cenderung memiliki kemampuan dalam menyelesaikan masalah secara sistematis dan mengikuti informasi yang sudah ada. Individu FI memandang persoalan secara analitis, mampu menganalisis dan mengisolasi rincian yang relevan, mendeteksi pola, dan mengevaluasi secara kritis suatu persoalan (Yousefi, 2011).

Berdasarkan hasil observasi di SMP Negeri 2 Kepil menunjukkan bahwa pembelajaran matematika terkesan kurang menyentuh pada substansi pemecahan masalah, khususnya pada materi aritmetika sosial. Faktor-faktor penyebabnya yaitu, (1) Siswa cenderung mengalami kesulitan dalam memahami masalah matematika. (2) Kesulitan dalam penerapan rumus yang digunakan. (3) Metode pembelajaran yang biasa digunakan adalah metode ceramah dan jarang dilakukan pembelajaran secara berkelompok. Walaupun dilakukan secara berkelompok, tidak semua anggota kelompok menyampaikan ide dan pendapatnya yang artinya hanya didominasi oleh beberapa siswa saja. Sehingga, kemampuan siswa dalam memecahkan masalah masih kurang. Hal ini dilihat dari pekerjaan siswa dalam menyelesaikan soal uraian. Siswa hanya mensubtitusi nilai suatu rumus tertentu tanpa mengelaborasi pengetahuannya untuk memecahkan masalah. Hal ini diduga menyebabkan munculnya sikap ketidaksenangan siswa terhadap pelajaran matematika. Faktor-faktor penyebab kemampuan pemecahan masalah siswa dapat dilihat pada Gambar 1, Gambar 2, dan Gambar 3.

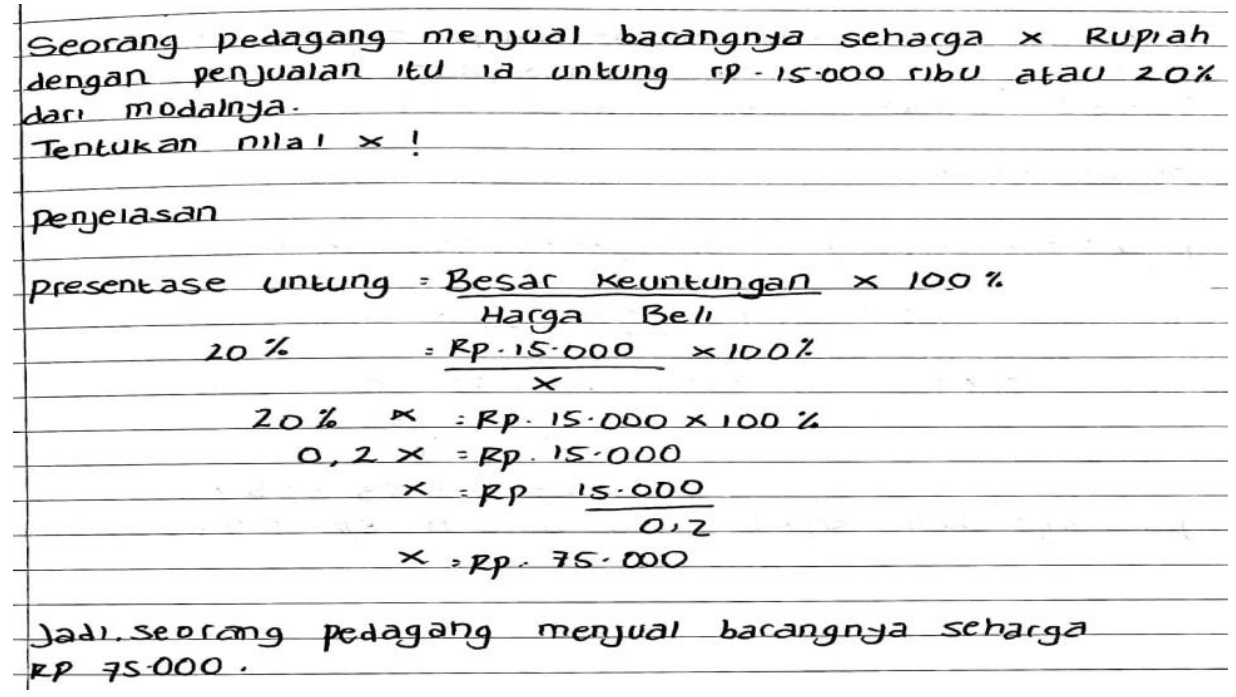

Gambar 1. Memahami masalah matematika 
Pengaruh Model Pembelajaran Cooperative Script dan Circ Dalam Kemampuan Pemecahan Masalah Ditinjau Dari Gaya Kognitif, Arum Marfungah, Puji Nugraheni, Dita Yuzianah

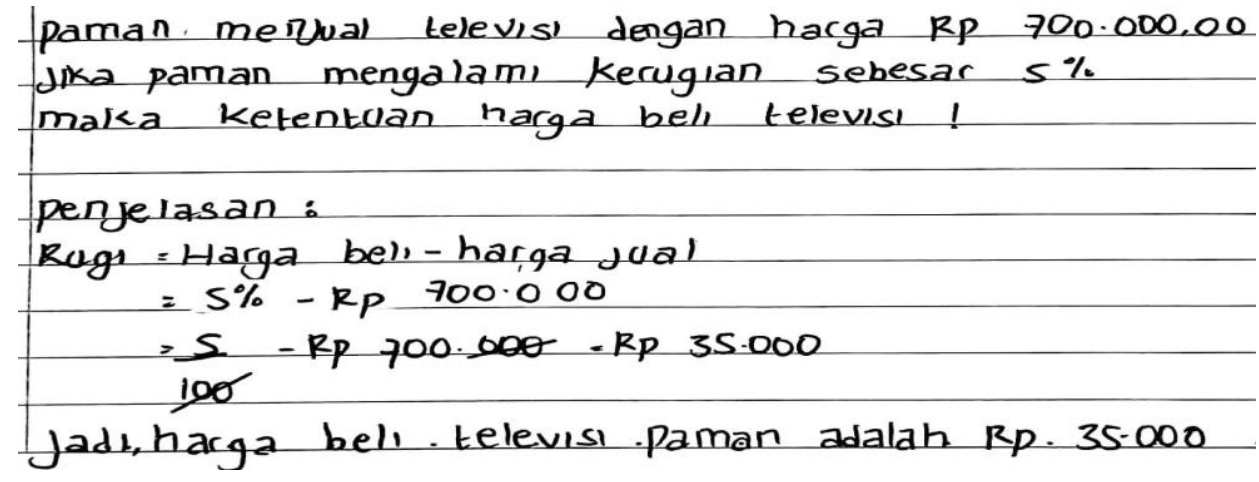

Gambar 2. Penerapan rumus

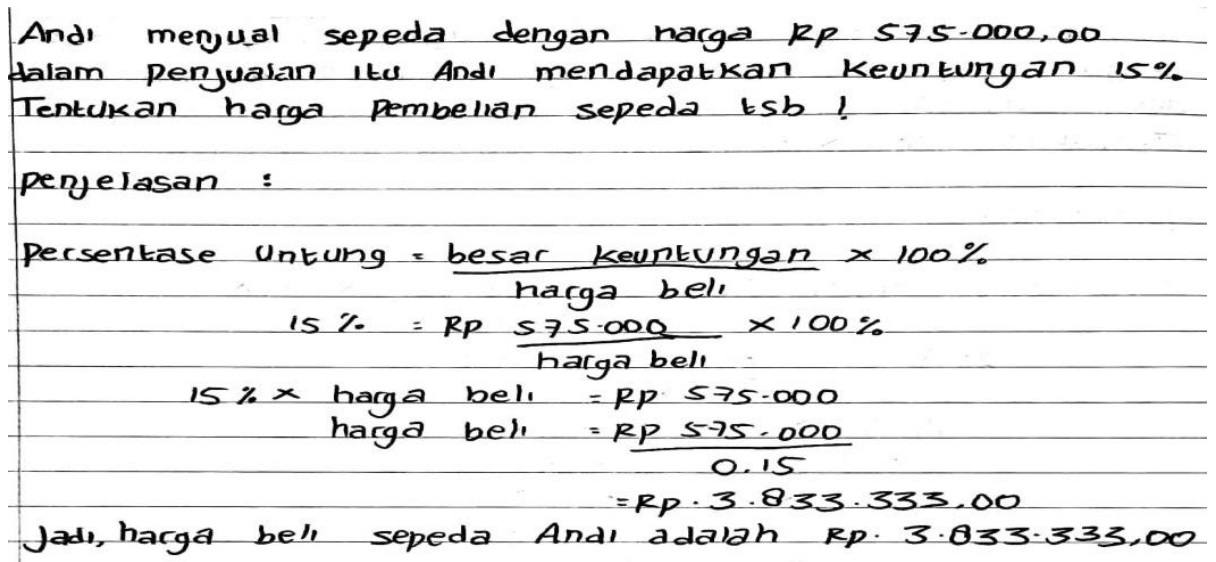

Gambar 3. Subtitusi Nilai Suatu Rumus

Oleh karena itu, diperlukan suatu model pembelajaran yang melibatkan siswa bekerjasama dalam kelompok untuk berbagi ide selama proses pemecahan masalah. Model pembelajaran yang mampu memenuhi hal tersebut diantaranya adalah model pembelajaran Cooperative Script dan Cooperative Integrated Reading and Composition (CIRC). Cooperative Script ditujukan untuk membantu siswa berpikir secara sistematis, berkonsentrasi dan memberdayakan potensi siswa untuk mengaktualisasikan pengetahuan dan keterampilannya dalam kemampuan pemecahan masalah (Azni, 2016). Sedangkan pada model Cooperative Integrated Reading and Composition (CIRC) siswa dituntut untuk menyelesaikan soal cerita kedalam bentuk perhitungan matematika agar memperoleh jawaban yang tepat dan dapat membantu siswa untuk mengasah kemampuan pemecahan masalah dalam menyelesaikan soal cerita. Sehingga dengan model pembelajaran tersebut siswa mampu dan terampil menyelesaikan masalah dalam soal cerita dengan langkah-langkah yang tepat (Siregar, 2016).

Dalam penelitian ini penulis mengacu pada penelitian terdahulu yang relevan dengan penelitian yang dilaksanakan pada saat ini. Penelitian dengan menggunakan model pembelajaran Cooperative Script dan Cooperative Integrated Reading and Composition (CIRC) sering dilakukan. Oleh karena itu, sebagai pembanding dan pertimbangan dengan penelitian ini. Penelitian yang relevan dengan penelitian ini adalah:

Kemampuan Pemecahan Masalah Matematika Siswa dalam Pembelajaran Matematika Menggunakan Model Pembelajaran Cooperative Script oleh Aisjah Juliana Noor dan Norlaila (2014). 
Diperoleh kesimpulan bahwa penerapan pembelajaran Cooperative Script memperoleh rata-rata sebesar 68,53 sedangkan rata-rata untuk kelas yang menggunakan pembelajaran langsung sebesar 49,57. Berdasarkan pemaparan diatas, menunjukkan bahwa model pembelajaran Cooperative Script lebih baik dari pada pembelajaran langsung.

Pengaruh Model Pembelajaran Cooperative Integrated Reading and Composition (CIRC) Terhadap Kemampuan Pemecahan Masalah Peserta Didik Materi Segitiga dan Segiempat Kelas VII MTS Ishthifaiyah Nahdliyah Pekalongan Tahun Pelajaran 2016/2017 oleh Zuhrotul Khasanah (2017). Diperoleh kesimpulan bahwa penerapan pembelajaran CIRC memperoleh rata-rata sebesar 63,11 sedangkan rata-rata untuk kelas yang menggunakan pembelajaran konvensional sebesar 55,5. Berdasarkan pemaparan di atas, menunjukkan bahwa model pembelajaran CIRC lebih baik daripada pembelajaran konvensional.

Kemampuan Pemecahan Masalah Matematis dengan Model Pembelajaran Cooperative Integrated Reading and Composition (CIRC) Ditinjau dari Kemampuan Awal Matematis Siswa oleh Riska dan Zubaidah Amir (2018). Diperoleh kesimpulan bahwa penerapan pembelajaran Cooperative Integrated Reading and Composition (CIRC) memperoleh nilai rata-rata sebesar 65,13 sedangkan rata-rata untuk kelas yang menggunakan pembelajaran langsung sebesar 55,39. Berdasarkan pemaparan di atas, menunjukkan bahwa model pembelajaran Cooperative Integrated Reading and Composition (CIRC) lebih baik dari pada pembelajaran langsung.

Hubungan Gaya Kognitif dengan Kemampuan Pemecahan Masalah Matematika Siswa oleh Himatul Ulya (2015). Diperoleh kesimpulan bahwa koefisien korelasi antara gaya kognitif dengan kemampuan pemecahan masalah matematika siswa (r_XY) sebesar 0,624 yang berarti bahwa terdapat hubungan positif dalam taraf tinggi antara gaya kognitif siswa dengan kemampuan pemecahan masalah siswa. Nilai koefisien determinasi 0,39 menunjukkan bahwa sebesar 39\% kemampuan pemecahan masalah siswa dipemgaruhi oleh gaya kognitif melalui hubungan linier sedangkan $61 \%$ dipengaruhi oleh faktor lain selain gaya kognitif.

Tujuan dari penelitian ini yaitu untuk mengetahui kemampuan pemecahan masalah matematika siswa dengan model pembelajaran Cooperative Script lebih baik dibandingkan model pembelajaran Cooperative Integrated Reading and Composition (CIRC) ditinjau dari gaya kognitif Field Independent (FI) dan Field Dependent (FD).

\section{METODE}

Jenis penelitian yang digunakan adalah penelitian eksperimental semu (quasi expeimental research). Budiyono (2019) menyatakan bahwa, "Tujuan penelitian eksperimental semu adalah untuk memperoleh informasi yang merupakan perkiraan bagi informasi yang dapat diperoleh dengan eksperimen yang sebenarnya dalam keadaan yang tidak memungkinkan untuk mengontrol data dan atau memanipulasikan semua variabel yang relevan". Peneliti hanya meneliti variabel yang dianggap dominan. Variabel yang dominan yang akan diteliti dalam penelitian ini adalah kemampuan 
Pengaruh Model Pembelajaran Cooperative Script dan Circ Dalam Kemampuan Pemecahan Masalah Ditinjau Dari Gaya Kognitif, Arum Marfungah, Puji Nugraheni, Dita Yuzianah

pemecahan masalah, gaya kognitif dan model pembelajaran. Jadi yang akan dilakukan dalam penelitian ini adalah membandingkan kelas eksperimen 1 dengan kelas eksperimen 2.

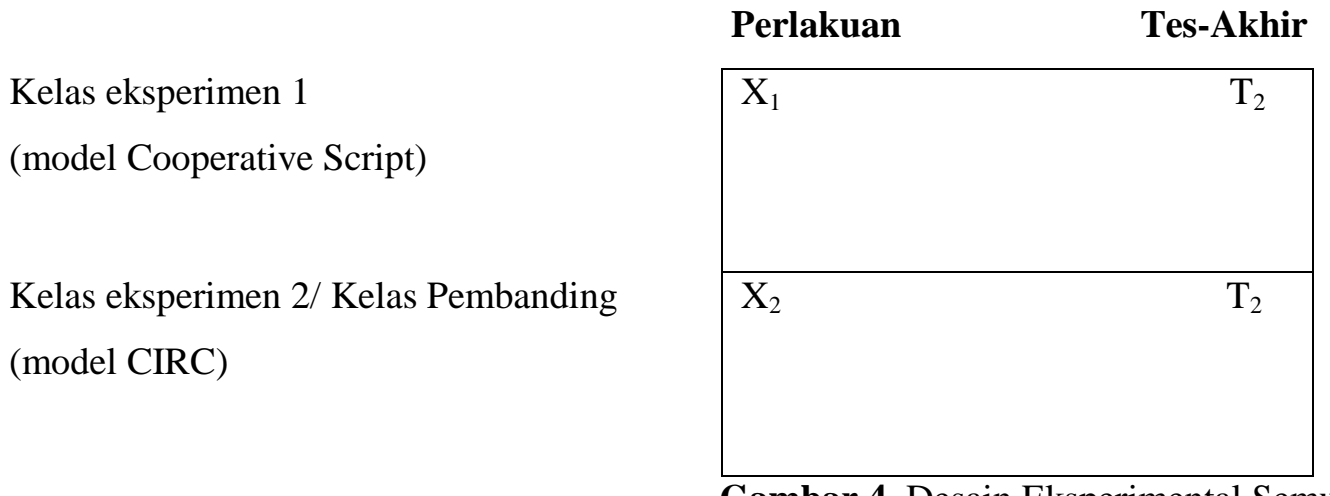

Gambar 4. Desain Eksperimental Semu

Populasi dalam penelitian ini yaitu seluruh kelas VII SMP Negeri 2 Kepil Tahun Pelajaran 2019/2020 yang berjumlah empat kelas yaitu kelas VII A, kelas VII B, kelas VII C, dan kelas VII D dengan jumlah 110 siswa. Pengambilan sampel dengan teknik simple random sampling. Sample dalam penelitian ini adalah 2 kelas yaitu kelas VII C sebagai kelas eksperimen 1 dengan model pembelajaran Cooperative Script dan kelas VII D sebagai kelas eksperimen 2 dengan model pembelajaran Cooperative Integrated Reading and Composition (CIRC). Instrumen yang digunakan dalam penelitian ini adalah tes gaya kognitif dan tes kemampuan pemecahan masalah.

Analisis data yang digunakan yaitu analisis data tahap awal dan analisis data tahap akhir. Analisis data tahap awal dilakukan untuk mengetahui kondisi awal sampel. Data yang di analisis diperoleh dari data penilaian akhir semester ganjil mata pelajaran matematika kelas VII SMP Negeri 2 Kepil tahun pelajaran 2019/2020. Analisis tahap awal meliputi uji normalitas, uji homogenitas, dan uji keseimbangan. Analisis data tahap akhir dilakukan untuk mengetahui kemampuan pemecahan masalah matematika siswa kelas eksperimen 1 dan kelas eksperimen 2. Data yang dianalisis diperoleh dari evaluasi aritmetika sosial pada kelas eksperimen 1 dan kelas eksperimen 2. Analisis data tahap akhir meliputi uji normalitas, uji homogenitas, dan uji hipotesis dengan anava dua jalur.

Instrumen Kemampuan Pemecahan Masalah:

1. Nana membeli buku di toko GRAMEDIA sebanyak 24 buah dengan harga Rp480.000,00. Kemudian semua buku itu dijual kembali dengan harga Rp16.000,00/buku. Apakah Nana mengalami kerugian? Jika benar Nana mengalami kerugian, berapa kerugiannya?

2. Ibu menjual tas dengan harga Rp240.000,00. Dari penjualan tersebut, Ibu mendapatkan untung 20\%. Tentukan harga beli tas tersebut!

3. Seorang pedagang sayur memperoleh hasil penjualam sebesar Rp108.000,00. Ternyata dia mengalami kerugian sebesar $10 \%$. Tentukan harga beli sayur tersebut! 


\section{HASIL}

Data skor gaya kognitif siswa dikumpulkan menggunakan Group Embedded Figure Test (GEFT) yang dilakukan sebelum pembelajaran. Hasil dari tes GEFT ditotal berdasarkan kategori yang telah ditentukan, dimana skor 0 sampai dengan 11 dikategorikan sebagai kelompok Field Dependent (FD) dan skor 12 sampai dengan 18 dikategorikan sebagai kelompok Field Independent (FI). Dari perhitungan skor gaya kognitif di dapat data mengenai gaya kognitif siswa pada kategori FI dan FD baik di kelas eksperimen 1 maupun kelas eksperimen 2. Pada kelas eksperimen 1 dan kelas eksperimen 2 jumlah siswa yang memiliki gaya kognitif FI masing-masing 12 siswa dan 14 siswa, sedangkan siswa yang memiliki gaya kognitif FD untuk kelas eksperimen 1 dan kelas eksperimen 2 masing-masing yaitu 13 siswa dan 11 siswa.

Data kemampuan pemecahan masalah dalam penelitian ini diperoleh dari data skor evaluasi aritmetika sosial pada kelas eksperimen 1 dan kelas eksperimen 2. Data evaluasi kelas eksperimen 1 mempunyai rata-rata 65,8 dengan standar deviasi 17,12 dan data evaluasi kelas eksperimen 2 mempunyai rata-rata 73,96 dengan standar deviasi 19,62.

Pengujian hipotesis menggunakan analisis variansi dua jalur yang dilanjutkan dengan uji lanjut pasca anava, dengan tujuan untuk melihat kelompok sampel mana yang lebih tinggi kemampuan pemecahan masalah matematika dari kelompok yang dibandingkan sehingga data sampel berlaku secara umum. Ringkasan hasil perhitungan analisis data dengan analisis variansi dua jalur dapat dilihat pada Tabel 1.

\section{Tabel 1.}

Rangkuman Analisis Variansi Dual Jalur

\begin{tabular}{|l|r|c|r|r|r|c|}
\hline Sumber & \multicolumn{1}{c|}{$\mathrm{JK}$} & $\mathrm{dk}$ & \multicolumn{1}{c|}{$\mathrm{RK}$} & \multicolumn{1}{c|}{$\mathrm{F}_{\mathrm{obs}}$} & \multicolumn{1}{c|}{$\mathrm{F}_{\alpha}$} & Ket \\
\hline Model Pembelajaran (A) & 510,74 & 1 & 510,74 & 9,42 & 4,08 & $\mathrm{H}_{0 \mathrm{~A}}$ Ditolak \\
\hline Gaya Kognitif (B) & 18512,52 & 1 & 18512,52 & 341,49 & 4,08 & $\mathrm{H}_{0 \mathrm{~B}}$ Ditolak \\
\hline Interaksi (AB) & 841,67 & 1 & 841,67 & 15,52 & 4,08 & $\mathrm{H}_{0 \mathrm{AB}}$ Ditolak \\
\hline Galat & 2494,06 & 46 & 54,21 & - & - & - \\
\hline Total & 22358,99 & 49 & - & - & - & - \\
\hline
\end{tabular}

Dari tabel 1 diatas diketahui bahwa $\mathrm{H}_{0 \mathrm{AB}}$ ditolak, sehingga dapat disimpulkan bahwa ada interaksi antara model pembelajaran dengan gaya kognitif siswa terhadap kemampuan pemecahan masalah matematika. Karena $\mathrm{H}_{0 \mathrm{AB}}$ ditolak, maka dilakukan uji lanjut pasca anava dengan uji komparasi ganda.

\section{Tabel 2.}

Rataan Antar Sel dan Rataan Marginal

\begin{tabular}{|c|c|c|c|}
\hline \multirow{2}{*}{ Model Pembelajaran } & \multicolumn{2}{|c|}{ Gaya Kognitif } & \multirow{2}{*}{ Rataan Marginal } \\
\cline { 2 - 3 } & FI & FD & \\
\hline Cooperative Script & 82,16 & 50,69 & 66,42 \\
\hline CIRC & 89,42 & 54,27 & 71,84 \\
\hline Rataan Marginal & 85,79 & 52,48 & \\
\hline
\end{tabular}


Pengaruh Model Pembelajaran Cooperative Script dan Circ Dalam Kemampuan Pemecahan Masalah Ditinjau Dari Gaya Kognitif, Arum Marfungah, Puji Nugraheni, Dita Yuzianah

Berdasarkan uji hipotesis komparasi ganda yang telah dilakukan, didapat bahwa rataan marginal kemampuan pemecahan masalah matematika siswa dengan model pembelajaran Cooperative Script pada siswa yang memiliki gaya kognitif FI dan FD adalah 66,42 dan rataan marginal kemampuan pemecahan masalah matematika siswa dengan model pembelajaran CIRC pada siswa yang memiliki gaya kognitif FI dan FD adalah 71,84. Dapat disimpulkan bahwa, model pembelajaran CIRC memberikan kemampuan pemecahan masalah yang lebih baik daripada model pembelajaran Cooperative Script pada siswa yang memiliki gaya kognitif FI dan FD. Shoimin (2017) model pembelajaran CIRC dapat meningkatkan hasil belajar khususnya dalam menyelesaikan soal yang berbentuk pemecahan masalah. Siregar (2016) CIRC dapat membantu siswa untuk mengasah kemampuan pemecahan masalah dalam menyelesaikan soal cerita. Sehingga dengan model pembelajaran CIRC siswa mampu dan terampil menyelesaikan masalah dalam soal cerita dengan langkah-langkah yang tepat. Selain itu, menurut Ruyaliningsih (2017) pembelajaran kooperatif tipe CIRC dapat dilakukan bersama-sama, sehingga peserta didik dalam kelompok secara aktif terlibat dalam menemukan permasalahan, kreatif berani bertanya, lebih percaya diri, dan lebih mudah menguasai materi pelajaran matematika. Hal ini didukung dengan hasil penelitian yang dilakukan oleh

Marviana, dkk (2018) yang menyatakan bahwa penerapan model pembelajaran CIRC lebih efektif terhadap kemampuan pemecahan masalah matematika. Hal ini disebabkan dalam proses pembelajaran kelas CIRC cenderung lebih antusias dalam diskusi kelompok (membaca bergantian, menemukan kata kunci, dan memberikan tanggapan) terhadap materi yang didiskusikan dibandingkan dengan pembelajaran Cooperative Script yang berdiskusi secara berpasangan, hal ini memungkinkan beberapa siswa takut untuk mengeluarkan ide karena akan dinilai oleh teman dalam kelompoknya. Dalam pelaksanaan diskusi tidak semua siswa fokus dalam pembelajaran dan beberapa kelompok tidak jarang mendiskusikan hal-hal yang tidak relevan. Hal ini diduga karena tingkat pemahaman masing-masing siswa berbeda serta kurangnya pemahaman siswa terhadap tugas yang diberikan.

\section{KESIMPULAN}

Berdasarkan hasil dan pembahasan dapat disimpulkan bahwa kemampuan pemecahan masalah matematika siswa dengan model pembelajaran Cooperative Script pada siswa yang memiliki gaya kognitif FI dan FD adalah 66,42 dan kemampuan pemecahan masalah matematika siswa dengan model pembelajaran CIRC pada siswa yang memiliki gaya kognitif FI dan FD adalah 71,84. Dapat disimpulkan bahwa, model pembelajaran CIRC memberikan kemampuan pemecahan masalah yang lebih baik daripada model pembelajaran Cooperative Script pada siswa yang memiliki gaya kognitif FI dan FD. Berdasarkan hasil penelitian, disarankan agar dalam menerapkan model pembelajaran CIRC, hendaknya guru menentukan siswa yang dianggap mampu menjadi pemimpin (ketua kelompok) dan anggota kelompok ditentukan oleh guru. 


\section{DAFTAR PUSTAKA}

Azni, A. (2016). Pengaruh Model Pembelajaran Cooperative Script Terhadap Hasil Belajar Matematika Siswa Kelas VII MTS Cerdas Murni Tembung Pada Pokok Bahasan Aritmetika Sosial Tahun Pelajaran 2014/2015. Jurnal AXIOM, V (1), 2087-8249.

Khasanah, Z. (2017). Pengaruh Model Pembelajaran Cooperative Integrated Reading and Composition (CIRC) Terhadap Kemampuan Pemecahan Masalah Peserta Didik Materi Segitiga dan Segiempat kelas VII MTs Ishthifaiyah Nahdliyah Pekalongan Tahun Pelajarn 2016/2017. Tesis. Semarang: Universitas Islam Negeri Walisongo.

Liu, Y. \& Ginther, D. (1991). Cognitive Style and Distance Education. Journal of Distance Learning Administration, 2 (3), 1-17.

Marviana, N.I., Wahyudi., \& Indriani, E. (2018). Efektivitas Model CIRC dan GGE Terhadap Kemampuan Pemecahan Masalah Matematika SD. Jurnal Sains dan Teknologi, 1(1), 89-94.

Noor, A. J. \& Norlaila. (2014). Kemampuan Pemecahan Masalah Matematika Siswa Dalam Pembelajaran Matematika Menggunakan Model Cooperative Script. Jurnal Pendidikan Matematika, 2 (3), 250-259.

Riska \& Amir, Z. (2018). Kemampuan Pemecahan Masalah Matematis dengan Model Pembelajaran Cooperative Integrated Reasing and Composition (CIRC) Ditinjau dari Kemampuan Awal Matematis. Journal of Medives, 2 (2), 225-233.

Ruyaliningsih. (2017). Pengaruh Cooperative Integrated Reading and Composition (CIRC) Terhadap Hasil Belajar Matematika. Jurnal Kajian Pendidikan Matematika, 2 (2), 2477-2348, 211-218.

Shoimin. A. (2017). 68 Model Pembelajaran INOVATIF dalam Kurikulum 2013. Yogyakarta: ArRuzz Media.

Siregar, Y.A. (2016). Penerapan Model Pembelajaran Kooperatife Tipe CIRC (Cooperative Integrated Reading and Composition) untuk Meningkatkan Kemampuan Siswa dalam Memecahkan Masalah Di SMP Negeri 1 Sipirok. Jurnal Eksakta, 1.

Slameto. (2015). Belajar dan Faktor-faktor yang Mempengaruhinya. Jakarta: Rineka Cipta.

Suparta, I.N., Irawan, I.P.E. \& Suharta, I. N. (2016). Faktor-faktor yang mempengaruhi Kemampuan Pemecahan Masalah Matematika. Pengetahuan Awal, Apresiasi Matematika, dan Kecerdasan Logis Matematis. Prosiding Seminar Nasional, ISBN 978-602-6428-00-4.

Ulya, H. (2015). Hubungan Gaya Kognitif Dengan Kemampuan Pemecahan Masalah Matematika Siswa. Jurnal Konseling GUSIJANG. 1 (2), 2460-1187.

Yousefi, M. (2011). Cognitive Style and EFL Learners' Listening Comprehension Ability. Indonesian Journal Of Apllied Linguistics. 1 (1), 1-17. 